\title{
Features of the Secondary Structure of BSA - Containing Protein Complexes, Isolated from Milk of High
}

\section{Temperature Processing}

\author{
Ivan S. Shatalov ${ }^{1}{ }^{*}$, Aleksandrina S. Shatalova ${ }^{1}$, Lyudmila V. Plotnikova ${ }^{2}$, \\ and Aleksandr G. Shleikin ${ }^{3}$ \\ ${ }^{1}$ Faculty of Food Biotechnologies and Engineering, Saint Petersburg National Research University of Information \\ Technologies, Mechanics and Optics, 49A Kronverksky Pr., Saint Petersburg 197101, Russia \\ ${ }^{2}$ Department of Physics, Saint Petersburg State University, 13B Universitetskaya Emb., Saint Petersburg 199034, \\ Russia \\ ${ }^{3}$ Research and Educational Center of Chemical Engineering and Biotechnology, Saint Petersburg National Research \\ University of Information Technologies, Mechanics and Optics, 49A Kronverksky Pr., Saint Petersburg 197101, Russia \\ * e-mail: shataloff.iv@gmail.com
}

\begin{abstract}
Present paper describes features of the component composition in the secondary structure of BSA-containing protein complexes isolated from ultra-pasteurized (UHT), sterilized (SHT) and powdered (DRY) milk. We have found $\beta$-sheets to present in all complexes investigated. However, the smallest number of such components have been revealed in samples derived from sterilized milk with less $\beta$-sheets in $1621-1626 \mathrm{~cm}^{-1}$ region. The composition study of the complexes originated from UHT milk has shown random coils to be the rarest in them. When considering the structure of the complexes isolated from powdered milk, the $\alpha-310$-helices were more characteristic for such samples, then the $\alpha$ - helix. Moreover, during spraydrying, the number of random structures increase with a simultaneous decrease in the number of $\beta$ - sheets, whereas in UHT - and SHT - processing the number of random structures is inversely proportional to the number of $\alpha$ - helices. (C) 2021 Journal of Biomedical Photonics \& Engineering.
\end{abstract}

Keywords: milk protein complexes; heat treatment; BSA; secondary structure.

Paper \#3413 received 12 Apr 2021; accepted for publication 3 Jun 2021; published online 30 Jun 2021. doi: 10.18287/JBPE21.07.020307.

\section{Introduction}

Due to its high nutritive value, milk is a useful and popular food product worldwide. Therefore, the development of preservation methods along with the means to maximize its nutritional value is a trend in the food industry. Today, main technological approaches are based on high temperature treatment aimed at removing pathogenic microflora. Table 1 shows the main temperature diapasons of heat treatments, which are currently used for long-term milk preservation.

Milk proteins undergo certain changes of their conformation under technological conditions.
However, the rate and nature of alterations vary drastically and depend not only on the chemical composition, but also on the structural organization of a protein globule.

Table 1 General Milk Processing Parameters.

\begin{tabular}{ccc}
\hline $\begin{array}{c}\text { Type of the } \\
\text { Heat- } \\
\text { Treatment }\end{array}$ & $\begin{array}{c}\text { Heating } \\
\text { Temperature, } \\
\mathbf{o}^{\mathbf{C}}\end{array}$ & $\begin{array}{c}\text { Incubation } \\
\text { time, sec }\end{array}$ \\
\hline UHT & $\sim 135-143$ & $0.4-4[1]$ \\
SHT & $\sim 115-120$ & $900-1200[1]$ \\
Spray drying & $\sim 150-200$ & Few sec. [1-3] \\
\hline
\end{tabular}


Milk proteins undergo certain changes of their conformation under technological conditions. However, the rate and nature of alterations vary drastically and depend not only on the chemical composition, but also on the structural organization of a protein globule.

Whey proteins are the most thermolabile. Because of the different component composition of the secondary structure, the presence of SS/SH - groups and bonds and the presence of metal ions, thermal stability decreases in the series $\alpha-$ actalbumin $>\beta-$ lactoglobulin $>$ BSA [4-6].

Among whey proteins BSA is one of the least thermally stable, denaturing irreversibly already at $57-59^{\circ} \mathrm{C}$. However, the conformational changes occurring twice: at $57^{\circ} \mathrm{C}$ and $75^{\circ} \mathrm{C}$ [7]. In its native state this protein contain no $\beta$-sheets but mainly $\alpha$-helices [8], It loses them together with $\beta$-turns at $57{ }^{\circ} \mathrm{C}$, while at temperatures above $70{ }^{\circ} \mathrm{C}$ irreversible intramolecular $\beta$ - sheets are formed [7]. Since this protein contains free thiol group at Cys34, which is hidden inside the hydrophobic pocket in native globule, but exhibited at denaturation [6], $\mathrm{SS} / \mathrm{SH}$ - exchange reactions are also an important factor in the formation of aggregates which includes this protein. On the other hand, BSA also forms protein complexes due to hydrophobic interactions with its surface. During the treatment with the temperatures higher than thermal denaturation, BSA is assumed to convert into a molten globule (MG), MG1. With further increase in temperature, MG1 slowly turns into MG2 - the structure with a more hydrophobic surface [9], which makes protein highly reactive [10]. Therefore, the aggregation of BSA proceeds mainly via two mechanisms: 1 - through the reactions of thiol-disulfide exchange, and 2 - hydrophobic interaction.

The more heat-resistant whey protein milk is $\beta$ - lactoglobulin. Although aggregating is mostly the result of SS/SH-exchange reactions, this process is mediated by a change of the secondary structure. Each individual globule mainly consists of anti-parallel $\beta$ - sheets formed by eight $\beta$ - chains wrapped around the molecule and forming a hydrophobic pocket, flanked by an $\alpha$-helix from its outer surface [11]. Separate $\beta$-chains are connected with two disulfide bridges: Cys66-Cys160 and Cys106-Cys119. Cys 121 possessing free $\mathrm{SH}$ - group is hidden inside the hydrophobic pocket under the $\alpha$-helix $[12,13]$. Partially irreversible denaturation of this protein occurs at $58-60^{\circ} \mathrm{C}$ and mainly affects the $\alpha-$ helix. Irreversible denaturation occurs at $63{ }^{\circ} \mathrm{C}$ and results in critical decrease in the $\beta$ - sheets content, followed by the exposure of hidden $\mathrm{SH}-$ group and the initiation of $\mathrm{SS} / \mathrm{SH}$ polymerization reactions of $\beta$ - lactoglobulin $[14,15]$. At this state $\beta$ - lactoglobulin is highly reactive and aggregates with milk proteins including BSA both via SS/SHexchange and hydrophobic interaction [16].

Possessing $\mathrm{Ca}^{2+}$ ion, $\alpha$-lactalbumin reversibly denatures up to $95^{\circ} \mathrm{C}$ [17]. Native $\alpha$-lactalbumin consists of two $\alpha$-helical domains, including four $\alpha$-helices and three $\alpha-3_{10}$-helices, as well as $\beta$ - sheet areas that include antiparallel $\beta$ - sheet and $\alpha-3_{10}-$ helix. Although this protein does not contain free thiol groups, during heat-treatment it can form aggregates through thiol-disulfide exchange reactions with other milk proteins, possessing available free$\mathrm{SH}$ - group (e.g denaturated BSA) [18]. These authors also reported the formation of hydrophobically stabilized aggregates of $\alpha$-lactalbumin and BSA during heating.

BSA is also known to form protein complexes with caseins, mainly with $\kappa$ - casein and to a lesser extent $\alpha \mathrm{S} 2$ - casein, formed via SS/SH-reactions [19-21]. In $\alpha \mathrm{S} 2$ - and $\kappa$ - casein mainly random coil, unordered structures, $\beta$ - sheets and $\beta$ - turns exist, but very little or no $\alpha$-helices. The formation of the latter structures is distorted due to the high content of non-polar amino acids (35-40\%), mainly proline [22, 23]. All caseins are phosphorylated in a various degree. Possessing of hydrophobic and hydrophilic regions together with the flexible structure, caseins are also capable of creating non-covalent intermolecular interactions [24-26].

This paper discusses the conformational features of protein complexes formed during various technological treatments of milk. Since BSA is one of the most thermolabile and reactive milk protein, the protein complexes containing it are the objects for this study.

\section{Materials and Methods}

Commercially available samples of spray-dried $(\mathrm{N}=9)$, UHT $(\mathrm{N}=12)$ and SHT $(\mathrm{N}=8)$ milk produced in Russia, Belarus and Finland were used for investigation. The fat content in samples was $25 \pm 5 \mathrm{~g} / \mathrm{L}$.

\subsection{Milk samples preparation before the analysis}

Dry milk samples were reconstituted with distilled water $(1: 10)$, followed by the supp 1 ementation with $1 \mathrm{~g} / \mathrm{L}$ preservative $(5$ - bromo -5 nitro -1.3 - dioxin, "Bronidox"). After that the samples were left for incubation overnight at $+4{ }^{\circ} \mathrm{C}$ for complete solubilization. The prepared samples were of $26 \mathrm{~g} / \mathrm{L}$ in fat content.

The preservative was also added to all samples of SHT and UHT milk.

All samples were centrifuged at 23,500 g during $50 \mathrm{~min}$ to exclude the lipids and insoluble aggregates. After that the supernatants were filtered through the Whatman 4 filter. The filtered solutions were used for affinity chromatography purification.

\subsection{Affinity chromatography}

Milk samples were applied to monoclonal anti-BSA antibody (clone X69, XEMA) coupled to NH2 - Agarose through Diels-Alder cycloaddition using TCO-NHS and tet-NHS pre-activation of antibody and resin (Click Chemistry Tools). Unbound 
matter was washed out with $0.1 \mathrm{~mol} / \mathrm{L}$ Tris, $\mathrm{pH} 7.2$. $0.4 \mathrm{~mol} / \mathrm{L} \mathrm{MgCl} 2$ in $0.1 \mathrm{~mol} / \mathrm{L}$ Tris, $\mathrm{pH} 7.2$ was used to elute BSA complexes.

\subsection{Sample preparation for electrophoretic analysis}

For further electrophoretic study the eluates were intensively dialyzed in two steps. The first dialysis was performed against $0.1 \mathrm{~mol} / \mathrm{L}$ Tris buffer $\mathrm{pH} 7.2$ containing $5 \mathrm{mmol} / \mathrm{L} \mathrm{Na}-$ EDTA using Vivaspin Turbo $450 \mathrm{MWCO}$ at $1200 \mathrm{~g}$ for $20 \mathrm{~min}$ to reach the final sample: buffer ratio $1: 1600$. The samples then were dialyzed against $0.1 \mathrm{~mol} / \mathrm{L}$ phosphate buffer, $\mathrm{pH}$ 7.2. All buffers contained $0.5 \mathrm{~g} / \mathrm{L} \mathrm{NaN}_{3}$ as a preservative.

\subsection{Determination of protein concentration}

To obtain the samples of equal protein concentration we used the Pierce BCA kit (Thermo Scientific) with BSA as the standard.

\subsection{Gel electrophoresis}

SDS-PAGE in reducing (with 2ME) conditions was performed according to according to Laemmli method in a mini-chamber (BioRad). Briefly, the $120 \mathrm{~g} / \mathrm{L}$ polyacrylamide gel was used. Buffer solution used for electrophoresis contained Tris-glycine, $\mathrm{pH}$ 8.3, containing $1 \mathrm{~g} / \mathrm{L}$ sodium dodecyl sulfate (SDS). The $0.06 \mathrm{~mol} / \mathrm{L}$ Tris- $\mathrm{HCl}$ buffer, containing $1 \mathrm{~g} / \mathrm{L}$ SDS, glycerol and bromophenol blue, $\mathrm{pH} 6.8$ was used as a sample buffer. Samples containing $1 \mathrm{mg} / \mathrm{ml}$ total protein were applied to the gel in a volume of $20 \mu \mathrm{l}$ well. Electrophoresis was carried out for $2 \mathrm{~h}$ at a current of $30 \mathrm{~mA}$. The starting voltage was $40 \mathrm{mV}$, which was increased to $150 \mathrm{mV}$ after the sample entered the upper gel. After the front of the samples reached the middle of the gel the voltage was increased to $210 \mathrm{mV}$. After the run was complete, the gels were fixed in $500 \mathrm{ml} / \mathrm{L}$ ethanol for $30 \mathrm{~min}$, after that they were washed three times with deionized water. The gel was stained with Coomassie brilliant blue G250. To decrease background the stained gels were washed with $100 \mathrm{~g} / \mathrm{L}$ acetic acid overnight with constant agitation at $400 \mathrm{rpm}$.

\subsection{MALDI-TOF}

Protein bands were cut from the gel for MALDI-TOF analysis. The procedure was conducted at the Institute of Biomedical Chemistry, Moscow. All reagents were purchased at Sigma-Aldrich (Moscow, Russia).

The procedure was described previously [27]. Briefly, the gel cuts were washed twice with $50 \%$ acetonitrile solution in $0.1-\mathrm{M} \mathrm{NH} 4 \mathrm{HCO} 3$ for $20 \mathrm{~min}$ at $37^{\circ} \mathrm{C}$ followed by dehydration with acetonitrile for $5 \mathrm{~min}$. The tryptic digestion was performed with $5 \mu \mathrm{L}$ of enzyme in $0.1-\mathrm{M} \mathrm{NH} 4 \mathrm{HCO} 3$ for $4 \mathrm{~h}$ at $37^{\circ} \mathrm{C}$ with subsequent peptide extraction with $0.7 \%$ TFA. The extracts obtained were analyzed using MALDI-TOF mass spectrometry.

To obtain mass spectra of digests MALDI-TOF/TOF mass-spectrometer (Ultrafle II, Bruker Daltonics, Germany) equipped with an $\mathrm{Nd}$ : YAG laser in the reflector mode was used. The measurement of monoisotopic $[\mathrm{MH}+]$ ions was conducted in the $700-4500 \mathrm{~m} / \mathrm{z}$ range with a tolerance of $70 \mathrm{ppm}$. The lift mode was used to obtain fragment ion spectra. The accuracy of fragment ion mass peak measurements was within $1 \mathrm{Da}$.

Spectral data analysis was performed via FlexAnalysis 3.3 software (Bruker Daltonics, Germany). To identify individual proteins MASCOT search software. Reliably identified proteins had the scores of $>82(\mathrm{p}<0.05)$ with the use of "peptide fingerprint" option and $>55(p<0.05)$ with the use of "ion score" option. The search was conducted in National Center for Biotechnology Information (NCBI) databases or EST (expressed sequence tag) plant database or both.

\subsection{FT-IR spectroscopy}

To record the absorption spectra in the mid-IR range, a Tensor 37 Fourier spectrometer (Bruker, Germany) was used in combination with an ATR-instrument based on a ZnSe crystal. The ATR spectra were corrected automatically using the software provided (Opus Software). The spectra of each sample were recorded with a resolution of $2 \mathrm{~cm}^{-1}$ and averaged over 256 accumulations. From the obtained absorption spectra, we subtracted the spectrum of the buffer solution $(0.1 \mathrm{~mol} / \mathrm{L}$ phosphate buffer, $\mathrm{pH} 7.2+0.5 \mathrm{~g} / \mathrm{L} \mathrm{NaN} 3)$, selecting the subtraction coefficient in such a way as to achieve a smooth baseline in the region of $2000-1800 \mathrm{~cm}^{-1}$ [28]. The protein concentration in the samples was at least $5 \mathrm{mg} / \mathrm{ml}$.

The obtained spectrum at this site was smoothed by 15 points using the Savitzky-Golay algorithm. Second derivative allowing us to determine the hidden absorption peaks, we used it to transform the spectrum according to Gauss.

\subsection{Data processing}

ATR-FTIR spectrograms were processed with Origin Lab 2016.

Statistical processing of the results obtained and data plotting were performed using RStudio with the packages "ggplot", "ggpubr", "scales". In boxplots, 


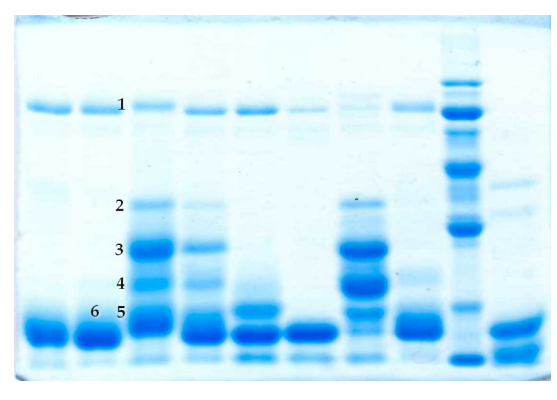

(a)

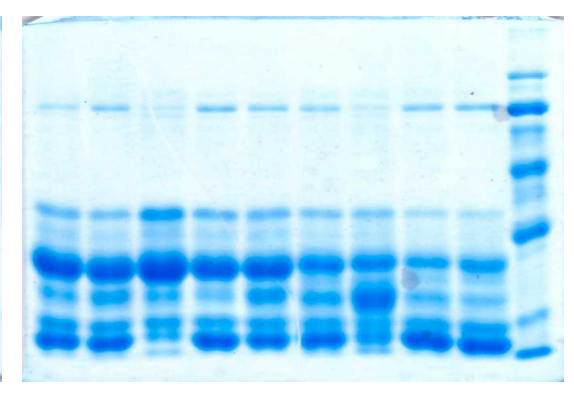

(b)

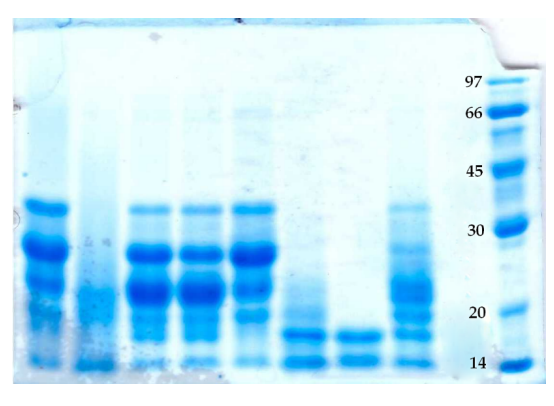

(c)

Fig. 1 Electrophoretic study of the BSA-complexes from: (a) DRY-,(b) UHT-, (c) SHT-milk: 1-BSA;2- $\alpha-\mathrm{S} 1-$ casein (dimer); 3 - beta casein, precursor; 4 - beta casein; $5-\kappa$ - casein; $6-\beta$-lactoglobulin (monomer). Molecular weight marker (vertical): 97, 66, 45, 30, 20, $14 \mathrm{kDa}$. The composition of each band observed was performed via MALDI - TOF.

Table 2 The contingency of bands presence at a given Amide 1 region.

\begin{tabular}{ccc}
\hline Treatment type & \multicolumn{2}{c}{$\begin{array}{c}\text { Absorption at the region } \\
\left(\mathrm{cm}^{-1}\right)\end{array}$} \\
\cline { 2 - 3 } & N observations & $\begin{array}{c}\text { N total }- \\
\mathrm{N} \text { observations }\end{array}$ \\
\end{tabular}

the values being higher than $4 \times \mathrm{IQR}$ (interquartile range) were treated as outliers.

To perform Barnard's exact test, the "Exact" package was used. The structure of contingency tables to be analyzed with Barnard's exact test is described in Table 2.

\section{Results}

\subsection{BSA-containing protein complexes from SHT-milk showed lowest content of $\beta$-sheets}

To investigate the qualitative composition of the BSA-containing protein complexes from milk we have performed electrophoretic analysis, the results of which showed not only the presence of BSA, but also other proteins that are the usual constituents of milk (Fig. 1), and their content in the complexes varied in samples depending on the source. The most homogeneous in composition were the complexes from UHT-milk.

To study the secondary structure, the Amide I region, located at the $1700-1600 \mathrm{~cm}^{-1}$, was investigated. At this region "stretching" vibrations of peptide bonds $\mathrm{C}=\mathrm{O}$ (approximately $80 \%$ ) and $-\mathrm{NH}$ (about 20\%) occur. The frequency of absorption and extraction of this band in this area depend on the origin of hydrogen bonds between $-\mathrm{CO}$ and $-\mathrm{NH}$, making this area extremely sensitive to conformational changes of the protein molecule [29]. Quantitative study of this area initially assumes that it can be represented as a linear sum of several fundamental structural components: $\alpha$ - helices, $\beta$ - sheets, random structures, etc. It is worth noting that the intensity of individual component absorption in the Amide I region is quite low, and individual peaks overlaps. Thus, under such conditions it is impossible to draw a certain conclusion about the quantitative and qualitative structural profile of the sample investigated. To overcome this problem various methods of signal amplification are used. In this paper we used the second derivative of the resulting spectrum, which allowed us to find hidden absorption peaks.

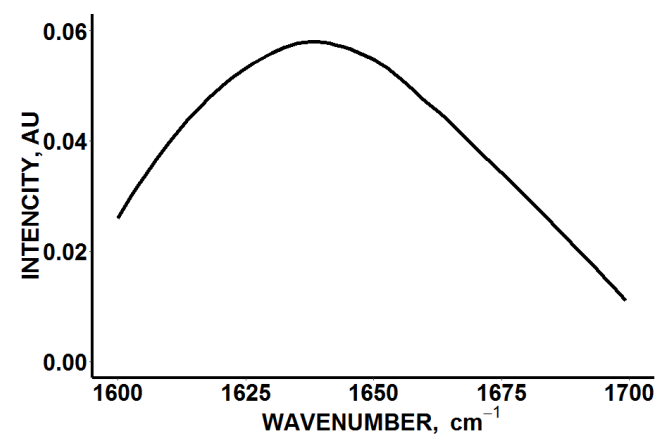

(a)

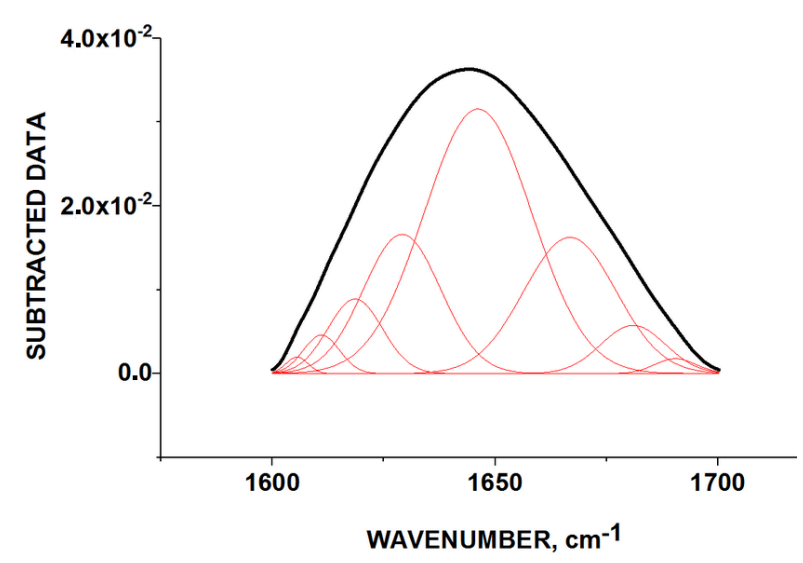

(b)

Fig. 2 (a) A typical FT-IR spectrogram of the Amide I region of protein complexes isolated from milk; (b) the result of decomposition of the Amide I region into subcomponents. 
Fig. 2 shows typical diagram of the FT-IRspectroscopy of the Amide I region of the protein complexes investigated. Fig. 2(a) illustrates that the absorption peak is centered around $1640 \mathrm{~cm}^{-1}$, which was noticed for all samples regardless of the processing source. In this area both $\beta$-sheets and random coils are absorbed.

In order to further interpret the results obtained and clarify the component composition of the spectrograms obtained we found the second derivative for each spectrum (Fig. 2b).

From its wavenumber each peak attributes to a specific structure, i.e. $\alpha$-helix, $\beta$-sheets, random coils, since each of the secondary structure has its own vibration. As Amide I is the sum of all the individual structures, it is also possible to reveal the contribution of a particular structure to the total absorption. This allowed us to conclude on the quantitative composition for the secondary structure of the samples studied. In this paper, the wavenumbers are correlated with a specific structure as shown in Table 3 .

Table 3 The main spectral bands characteristic for the secondary structures

\begin{tabular}{ccc}
$\begin{array}{c}\text { Secondary } \\
\text { structure }\end{array}$ & Wavenumber, $\mathbf{c m}^{-1}$ & Reference \\
\hline$\beta$-sheet & $1620-1639$ & {$[29-31]$} \\
\hline$\alpha-$ helix & $1650-1660$ & {$[32]$} \\
\hline Random coil & $1640-1650$ & {$[29-31]$} \\
\hline$\alpha-310-$ helix & $1660-1666$ & {$[33]$} \\
\hline$\beta-$ turn and \\
$\beta-$ loop & $1667-1688$ & {$[30]$} \\
\hline $\begin{array}{c}\text { Intermolecular } \\
\beta-\text { sheet }\end{array}$ & $1615-1620$ & {$[34-36]$} \\
\hline
\end{tabular}

Fig. 3 shows the heat map of the absorption peaks prevalence at the Amid I region for BSA-containing protein complexes isolated from milk of various processing temperatures.

As can be seen, the areas of $\beta$ - sheets absorbance 1614-1620, 1627-1639, 1678-1695 $\mathrm{cm}^{-1}$ were observed in all of the complexes studied. On the other hand, the presence of absorption peaks in the areas of 1621-1626, 1640-1650, 1651-1658, and $1660-1664 \mathrm{~cm}^{-1}$ varies depending on the milk treatment used. To investigate the significance of the differences observed at these regions we compiled sets of contingency tables. These tables were analyzed using the Barnard's exact test, which is similar to Fisher's exact test, but with greater power analyzing $2 \times 2$ contingency tables with a small number of observations [37]. The results of the Barnard's exact test are shown in Table 4.

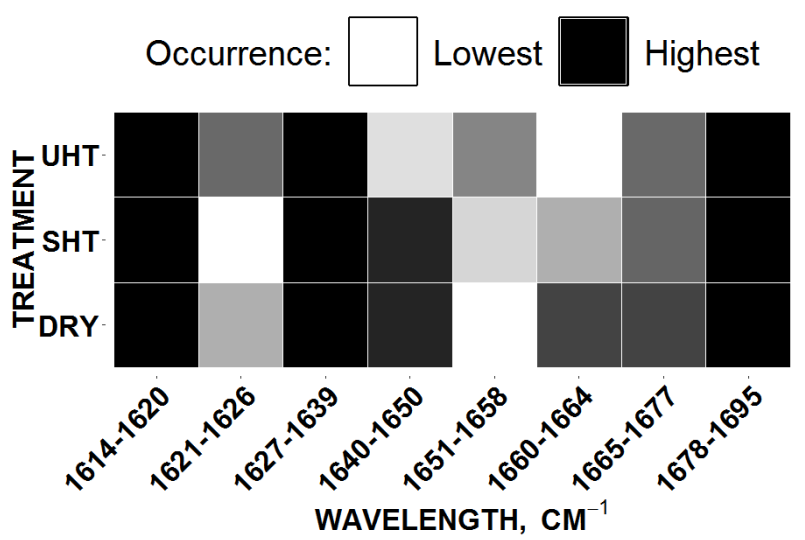

Fig. 3 Occurrence frequency of absorption peaks of the Amide I region in the BSA-containing protein complexes isolated from milk of various heat treatments. The higher the density (black color) is, the more frequent the occurrence.

Table 4 Comparison of the structure occurrence at the given Amide I region in the samples depending on the treatment applied

\begin{tabular}{ccccc} 
Range, $\mathbf{c m}^{-\mathbf{1}}$ & $\begin{array}{c}\text { Treatment type } \\
\text { comparison }\end{array}$ & N observations & N total & $\begin{array}{c}\text { P-value } \\
\text { (Barnard' test) }\end{array}$ \\
\hline \multirow{2}{*}{$1621-1626$} & UHT vs SHT & 8 vs 1 & 12 vs 8 & 0.023 \\
\hline \multirow{2}{*}{$1640-1650$} & UHT vs DRY & 8 vs 4 & 12 vs 9 & 0.356 \\
& UHT vs SHT & 4 vs 7 & 12 vs 8 & 0.023 \\
\hline $1660-1664$ & UHT vs DRY & 4 vs 8 & 12 vs 9 & 0.012 \\
\hline
\end{tabular}


At all the regions considered the absorption peaks of BSA-containing complexes from dry and sterilized milk the significant differences in their abundance were not found. In addition, when analyzing the frequency of peak occurrence at the region of $1651-$ $1658 \mathrm{~cm}^{-1}$ all the complexes showed no significant differences between each group. On the other hand, when analyzing the area of $1640-1650 \mathrm{~cm}^{-1}$, in which oscillations of random structures are observed, the lowest abundance of such structures was found in the complexes originated from UHT-milk, while such structures were shown to present in all complexes from sterilized and dried milk. At the region of $1660-1664 \mathrm{~cm}^{-1}$, where $\alpha-3_{10}$ - helices are usually observed, when comparing complexes from dry and UHT milk for the latter these structures were statistically less common.

The analysis of $1621-1626 \mathrm{~cm}^{-1}$ region showed the smallest presence of absorption peaks for complexes isolated from sterilized milk. Absorption in this area is also associated with the presence of intermolecular $\beta$-sheets of unfolded protein components formed during heat treatment [38]. According to Ref. [39], absorption at this site is characteristic of intermolecular amyloid-like structural components.

Considering the heat map analysis, it can be concluded that although the absorption profiles were distributed similarly, there is a number of significant differences between the samples of the complexes resulting from different processing. The displacement towards the higher wave numbers of the structural profile in protein complexes isolated from dry milk was the most common characteristic among all the samples studied. Generally, the density distribution of wavenumbers in this profile was shifted to the right, which is clearly noticeable when analyzing the region of $\alpha$-helices $\left(1651-1658 \mathrm{~cm}^{-1}\right)$. These samples had the highest density of $\alpha-310$-helices located at $1660-1664 \mathrm{~cm}^{-1}$ region, which indicates a trend to the " $\alpha$-helices $\rightarrow \alpha-3_{10}$ - helices" shift in them. Being typical for certain milk proteins, for example,

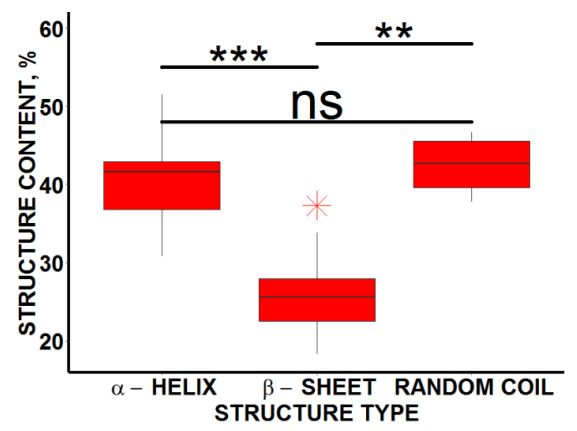

(a)

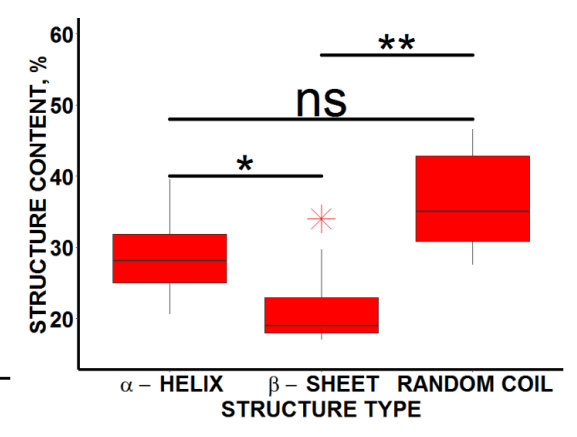

(b) $\alpha$ - lactalbumin [40], the presence of $\alpha-3_{10}-$ helices in this case can be attributed to the result of denaturation changes taking place in the milk proteins during drying.

Comparing samples originated from UHT- and SHT-milk it is noticeable that both groups had little differences at the region of $\alpha$-helices, however, the greatest variety in the presence of such structures are found at the region of random coil. Such structures we shown to be more typical for samples from sterilized milk. The same observation for this region was also valid for the samples isolated from dry milk, where the presence of random structures was characteristic in all the considered cases. It can be concluded that the formation of random coil was not typical for the UHT processing, in which the high-temperature effect is of short duration.

\subsection{Random coil was the prevalent structure for all types of BSA-complexes}

The quantitative analysis of the secondary structure components in the samples under consideration showed their uneven distribution (Fig. 4). The components with vibrations in the range of $1642-1660 \mathrm{~cm}^{-1}$ were shown to have the greatest contribution, which was also observed in the original spectrograms. Both random coil and $\alpha-$ helix vibrate in this region.

To evaluate the ratio of the contribution of each secondary structure and the level of its significance, Fig. 4 shows the quantitative structural compositions in the studied protein complexes originated from milk of various heat treatments. In the complexes investigated, the contribution scatter of the random coil to the secondary structure of protein aggregates originated from dry milk was the widest among both the type of processing applied and the contributions of other structures under consideration (Table 5).

Fig. 4 Quantitative distribution of structural components in samples of complexes isolated from milk of various technological processing: (a) UHT-milk, (b) SHT-milk, (c) spray-dried milk. Red asterisk denotes outliers, Black indicates Mann-Whitney test significance levels: “ns" $-\mathrm{p}>0.05 ;$ “*”- $\mathrm{p} \leq 0.05 ;$ “**" $-\mathrm{p} \leq 0.01 ;$;***" $-\mathrm{p} \leq 0.001$; “****" $-\mathrm{p} \leq 0.0001$. 
All complexes investigated were shown to have the greatest number of random structures, the smallest $\beta$-sheets $(p=0.0045)$ in their overall secondary structure. When considering complexes formed in UHT-milk, the difference in the content of $\beta$ - sheets and $\alpha$-helices is most pronounced $(p=0.001)$. The content of the latter in such complexes was high (about $40 \pm 6.4 \%$ ), and their distribution in the samples was rather narrow. Quantitatively, in all cases studied the content of $\beta$ - sheets was significantly smaller than the content of random structures $(\mathrm{p}=0.004)$.

The secondary structures in complexes from sterilized milk were distributed similarly to the ones of UHT-milk. $\beta$ - sheet content was smaller with respect to both random coil $(\mathrm{p}=0.001)$ and $\alpha$-helices $(\mathrm{p}=0.004)$.

The number of random coils in all the complexes studied was at the level of $37-43 \%$ and was not statistically different with respect to the treatment used, but the widest variation in quantity of such structures was found in the complexes isolated from dry milk, as noted above. This observation can be explained by the wider variety of temperature regimes used for the milk spray-drying implementation, leading to a higher variation of denaturation degree in milk proteins, which reflects in the secondary structure. Table 5 shows the $\beta$ - sheets possessed the least quantitative contribution into the secondary structure components of all the samples studied, being less than $30 \%$. Depending on the source of the complexes, they were distributed according to the principle of $\mathrm{SHT} \leq \mathrm{DRY} \leq \mathrm{UHT}$ : a smaller number of these structures in BSA-containing complexes from sterilized milk were found when compared with both complexes of UHT-milk $(p=0.005)$ and the ones isolated from dry milk $(p=0.03)$. Such an observation may be caused by the specificity of this technological process, as sterilization is not only high-temperature, but also the most long-term of the processes under consideration. Apparently, this alters the protein globules much stronger. The difference in the number of $\beta$ - sheets in the complexes of dry and UHT milk was not of statistical significance.

\section{$3.3 \alpha$-helices were more characteristic for protein complexes from UHT-milk, rather than for complexes of dry milk.}

Considering the content of $\alpha$-helices, it was found that the largest number of such components was characteristic to UHT-milk (Fig. 5). It should be noted, that the content difference was statistically significant for complexes of dry and UHT-milk $(\mathrm{p}=0.012)$, but insignificant for the aggregates of UHT- and SHT-milk. Thus, the mobility of such structures is affected by the dehydration taking place during the spray-drying of milk to a greater extent, rather than high temperature and exposure duration.

Table 5 The contribution of structural components in samples of milk proteins complexes obtained from the sources various heat treatment (mean $\pm \mathrm{SD}, \%$ )

\begin{tabular}{cccc}
\hline Treatment & $\boldsymbol{\beta}$ - sheet & Random coil & $\boldsymbol{\alpha}$ - helix \\
\hline UHT & $24.40 \pm 6.65$ & $42.48 \pm 4.18$ & $40.36 \pm 6.41$ \\
SHT & $16.66 \pm 3.01$ & $41.46 \pm 5.03$ & $28.51 \pm 3.88$ \\
DRY & $21.84 \pm 6.02$ & $37.04 \pm 7.52$ & $28.92 \pm 6.73$ \\
\hline
\end{tabular}

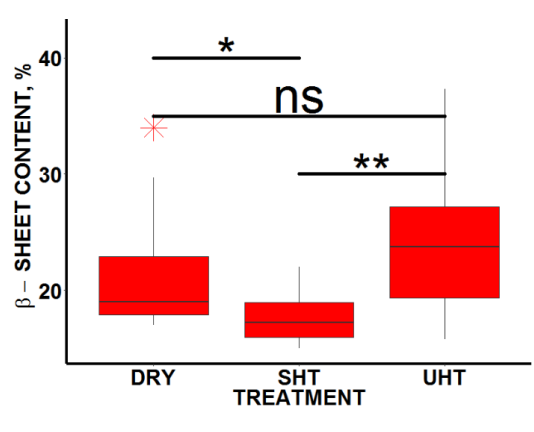

(a)

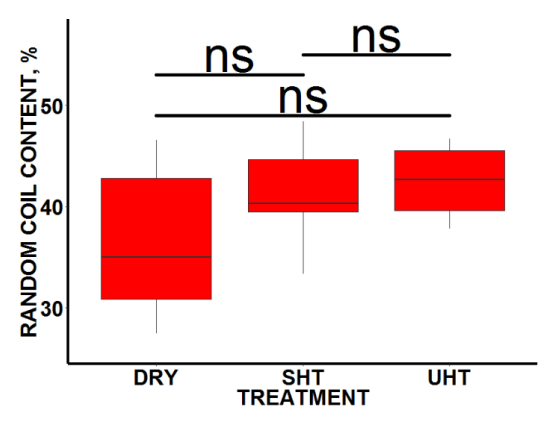

(b)

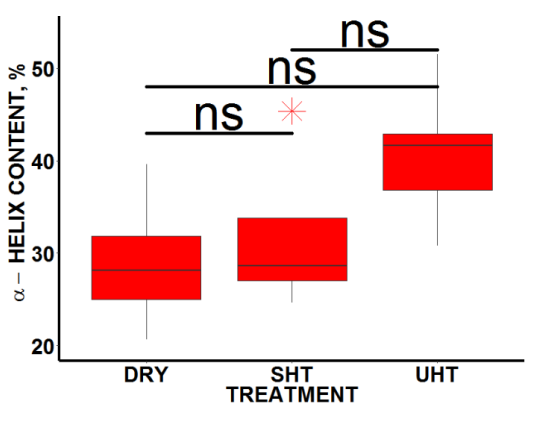

(c)

Fig. 5 Comparison of quantitative distribution of secondary structure in protein complexes depending on the type of processing used. Outliers are marked with a red asterisk, Mann-Whitney test significance levels are black: “ns" $-\mathrm{p}>0.05$; “*” $-\mathrm{p} \leq 0.05 ;$; “**” $-\mathrm{p} \leq 0.01$; “***” $-\mathrm{p} \leq 0.001$; “****” $-\mathrm{p} \leq 0.0001$. 


\subsection{Mutual conversion of secondary structure in protein complexes is affected by the type of heat treatment}

Among the major structural components, the presence of $\beta$ - sheets were detected in all complexes, but their number varied in the samples as mentioned above. Fig. 6 shows the mutual correlations of structural components in BSA-containing complexes of variously processed milk relative to the content of $\beta-$ sheets in it.

Although in some cases the dependencies are expressed implicitly (high p - value, Spearman), it is noticeable that samples from dry milk containing more $\beta$ - sheets in the Amide I region also contained more $\alpha$-helices (excluding $\alpha-310$ ). Controversially, such samples were shown to possess reduced the content of random coils. This observation could be explained as the mutual conversion of structural components in such samples.

An opposite situation was observed in the study of the structure contributions in complexes of sterilized and UHT milk. Random coils in such samples were found in greater amount, although they varied in the frequency of occurrence, which was mentioned above. Simultaneously, a decrease in the content of

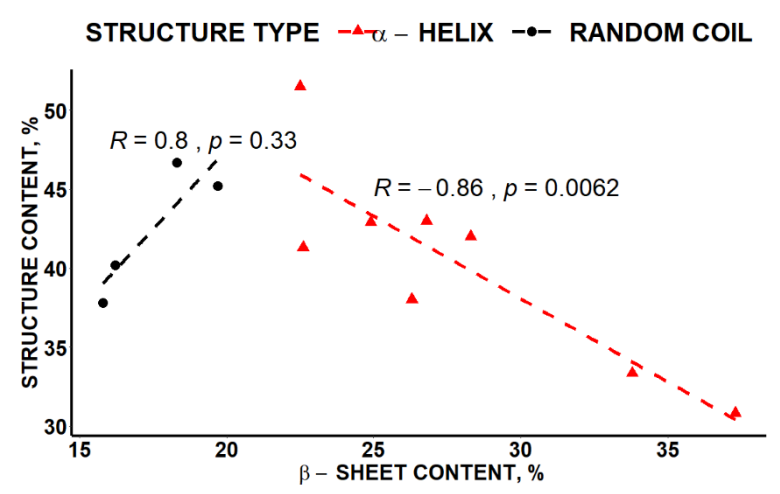

(a)

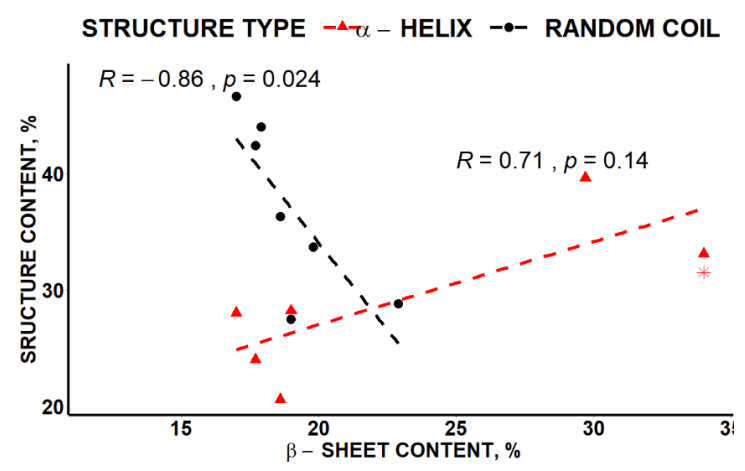

(c) $\alpha$-helices was observed in samples along with an increase in the content of $\beta$ - sheets.

During UHT processing, the protein complexes showed a decrease in the number of $\alpha$-helices, which correlates with an increase in the $\beta$-sheet content $(\mathrm{R}=-0.82)$. When considering the mutual correlation of the secondary structure components in complexes of sterilized milk, this tendency can be clearly seen. Thus, it can be concluded that $\alpha$-helices are converted into random coils in these two processing types.

Although the two methods, SHT- and UHTprocessing, vary greatly in their implementation, spray-drying causes an additional effect of dehydration, which obviously affects the profile of the secondary structure in protein complexes.

\section{Conclusion}

The study has found that the components of the secondary structure in BSA-containing protein complexes isolated from milk of various technological processing are unevenly distributed. All complexes studied were shown to contain $\beta$-sheets, but their quantitative contribution in all cases was small relative to the other secondary structures. The lowest content

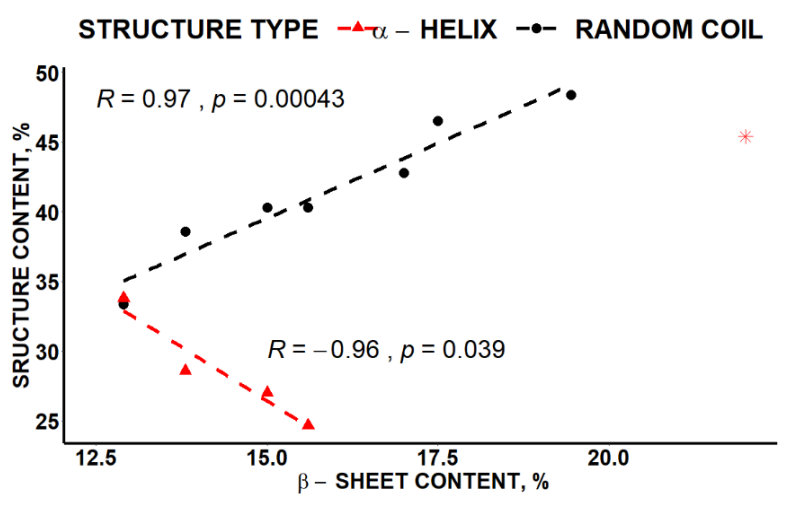

(b)

Fig. 6 Mutual correlation of secondary structure in complexes isolated from milk of various technological processing: (a) UHT-milk, (b) SHT-milk, (c) spray-dried milk. Triangle and circle depict $\alpha$-helices and random coil content, respectively. $\mathrm{R}$ reflects the Spearman correlation coefficient, $\mathrm{p}$ - the significance of correlation. The data marked with red asterisk were not considered. 
of $\beta$-sheets was found in SHT-milk, thus it can be concluded that it is the exposure time to high temperature that leads to a decrease in their content. For UHT- milk complexes, the smallest frequency in occurrence of random coils was also noted. This observation could be explained with the shortest incubation time at a high temperature in the process among those considered, preventing the formation of such structures. When comparing complexes of dry and UHT-milk, the presence of $\alpha-310-$ helices was more characteristic than $\alpha$ - helices for the complexes of the first treatment type. This fact also confirmed when comparing the quantitative contribution of $\alpha$-helices to the secondary structure of these complexes. Thus, dehydration during spray-drying could be concluded to promote the shift at this region towards large wave numbers.

The study of mutual correlation of the secondary structures quantitative contribution established similar models for UHT- and SHT-processes, differing from those, which occur during the spray-drying. Thus, in the samples of SHT- and UHT- treated milk samples, an increase in the number of random coils occurs with a decrease in the number of $\alpha$-helices, while during spray-drying the increase in random structures correlates with a decrease in the number of $\beta$ - sheets.

Based on the data described, the alteration of milk proteins' secondary structure during heat treatment is greatly defined by the certain type of technological processing. With further investigations this finding could be used for the improvement of identity control methods applied for dairy products.

\section{Abbreviations}

UHT: ultra-high-temperature; SHT: sterilization; DRY: spray drying; BSA: bovine serum albumin; TCO: trans-cycloocten-PEG4-NHS ester; 2ME: 2 - mercaptoethanol; Tz: methyltetrazine-PEG4NHS ester; DMSO: dimethyl sulfoxide; SDS: sodium dodecyl sulfate; ATR: attenuated total reflectance; FT-IR-spectroscopy: Fourier-transform infrared spectroscopy.

\section{Disclosures}

All authors declare that there is no conflict of interests in this paper.

\section{Acknowledgements}

We thank Olga Poleshchuk (EPAM Systems) for assistance with data processing and statistical analysis.

\section{References}

1. S. N. Moejes, A. J. B. van Boxtel, "Energy saving potential of emerging technologies in milk powder production," Trends in Food Science \& Technology 60, 31-42 (2017).

2. L. Malafronte, L. Ahrné, E. Schuster, F. Innings, and A. Rasmuson, "Exploring drying kinetics and morphology of commercial dairy powders," Journal of Food Engineering 158, 58-65 (2015).

3. Y. Lin, Y. Liu, L. Wang, Y. Xie, Z. Gao, and S. Wang, "Optimization of drying conditions and components to reduce wall sticking during spray drying of infant formula milk," International Journal of Agricultural and Biological Engineering 11(2), 214-218 (2018).

4. E. A. Permyakov, $\alpha$-Lactalbumin, Nova, New York (2005). ISBN 1-59454-107-8.

5. P. E. Morgan, T. M. Treweek, R. A. Lindner, W. E. Price, and J. A. Carver, "Casein proteins as molecular chaperones," Journal of Agricultural and Food Chemistry 53(7), 2670-2683 (2005).

6. V. A. Borzova, K. A. Markossian, N. A. Chebotareva, S. Y. Kleymenov, N. B. Poliansky, K. O. Muranov, V. A. Stein-Margolina, V. V. Shubin, D. I. Markov, and B. I. Kurganov, "Kinetics of Thermal Denaturation and Aggregation of Bovine Serum Albumin,” PLoS One 11(4), e0153495 (2016).

7. K. Murayama, M. Tomida, "Heat-Induced Secondary Structure and Conformation Change of Bovine Serum Albumin Investigated by Fourier Transform Infrared Spectroscopy," Biochemistry 43(36), 11526-11532 (2004).

8. S. Verruck, S. Sartor, F. B. Marenda, E. L. da Silva Barros, C. Camelo-Silva, M. H. Machado Canella, and E. S. Prudencio, "Influence of Heat Treatment and Microfiltration on the Milk Proteins Properties," Advances in Food Technology and Nutritional Sciences 5(2), 54-66 (2019).

9. S. K. Baier, E. A. Decker, and D. J. McClements, "Impact of glycerol on thermostability and heat-induced gelation of bovine serum albumin," Food Hydrocolloids 18(1), 91-100 (2004).

10. H. B. Wijayanti, N. Bansal, and H. C. Deeth, "Stability of Whey Proteins during Thermal Processing: A Review," Comprehensive Reviews in Food Science and Food Safety 13(6), 1235-1251 (2014).

11. G. B. Jameson, J. J. Adams, and L. K. Creamer, "Flexibility, functionality and hydrophobicity of bovine $\beta$ lactoglobulin," International Dairy Journal 12(4), 319-329 (2002).

12. K. Ponniah, T. S. Loo, P. J. B. Edwards, S. M. Pascal, G. B. Jameson, and G. E. Norris, "The production of soluble and correctly folded recombinant bovine beta-lactoglobulin variants A and B in Escherichia coli for NMR studies," Protein Expression and Purification 70(2), 283-289 (2010). 
13. R. N. W. Zeiler, P. G. Bolhuis, "Exposure of thiol groups in the heat-induced denaturation of $\beta$-lactoglobulin," Molecular Simulation 41(10-12), 1006-1014 (2015).

14. E. N. C. Mills, A. S. Tatham, "Allergenes," in Encyclopedia of Food Sciences and Nutrition, B. Caballero, P. M. Finglas, and F. Toldrá (eds.), $2^{\text {nd }}$ ed., Academic Press, New York, 143-150 (2003). ISBN: 978-0-12-227055-0.

15. D. Mercadante, L. D. Melton, G. E. Norris, T. S. Loo, M. A. K. Williams, R. C. J. Dobson, and G. B. Jameson, "Bovine $\beta$-Lactoglobulin Is Dimeric Under Imitative Physiological Conditions: Dissociation Equilibrium and Rate Constants over the pH Range of 2.5-7.5," Biophysical Journal 103(2), 303-312 (2012).

16. P. Havea, H. Singh, and L. K. Creamer, "Characterization of heat-induced aggregates of $\beta$-lactoglobulin, $\alpha-$ lactalbumin and bovine serum albumin in a whey protein concentrate environment," Journal of Dairy Research 68(3), 483-497 (2001).

17. A. M. Gil, "Nuclear Magnetic Resonance," in Encyclopedia of Food and Health, F. T. B. Caballero, P. M. Finglas (Eds.), Academic Press, New York (2003). ISBN: 978-0-12-384953-3.

18. P. Havea, H. Singh, and L. K. Creamer, "Formation of New Protein Structures in Heated Mixtures of BSA and $\alpha-$ Lactalbumin," Journal of Agricultural and Food Chemistry 48(5), 1548-1556 (2000).

19. L. Donato, F. Guyomarc'h, "Formation and properties of the whey protein/א-casein complexes in heated skim milk - A review," Dairy Science and Technology 89(1), 3-29 (2009).

20. F. Chevalier, A. L. Kelly, "Proteomic Quantification of Disulfide-Linked Polymers in Raw and Heated Bovine Milk," Journal of Agricultural and Food Chemistry 58(12), 7437-7444 (2010).

21. M. S. Mahomud, N. Katsuno, and T. Nishizu, "Formation of soluble protein complexes and yoghurt properties influenced by the addition of whey protein concentrate," Innovative Food Science \& Emerging Technologies 44, 173-180 (2017).

22. A. K. Dunker, C. J. Brown, J. D. Lawson, L. M. Iakoucheva, and Z. Obradović, "Intrinsic disorder and protein function," Biochemistry 41(21), 6573-6582 (2002).

23. T. F. Kumosinski, E. M. Brown, and H. M. Farrell, "Three-Dimensional Molecular Modeling of Bovine Caseins: An Energy-Minimized $\beta$-Casein Structure,” Journal of Dairy Science 76(4), 931-945 (1993).

24. T. K. Głąb, J. Boratyński, "Potential of Casein as a Carrier for Biologically Active Agents," Topics in Current Chemistry 375(4), 1-20 (2017).

25. T. M. Treweek, D. C. Thorn, W. E. Price, and J. A. Carver, "The chaperone action of bovine milk $\alpha \mathrm{S} 1-$ and $\alpha \mathrm{S} 2-$ caseins and their associated form $\alpha$ S-casein," Archives of Biochemistry and Biophysics 510(1), 42-52 (2011).

26. M. Ehrnsperger, S. Gräber, M. Gaestel, and J. Buchner, "Binding of non-native protein to Hsp25 during heat shock creates a reservoir of folding intermediates for reactivation," The EMBO Journal 16(2), 221-229 (1997).

27. A. M. Andreeva, A. S. Vasiliev, I. Y. Toropygin, D. V. Garina, N. Lamash, and A. Filippova, "Involvement of apolipoprotein A in maintaining tissue fluid balance in goldfish Carassius auratus," Fish physiology and biochemistry 45(5), 1717-1730 (2019).

28. J. R. Powell, F. M. Wasacz, and R. J. Jakobsen, “An Algorithm for the Reproducible Spectral Subtraction of Water from the FT-IR Spectra of Proteins in Dilute Solutions and Adsorbed Monolayers," Applied Spectroscopy 40(3), 339-344 (1986).

29. J. Kong, S. Yu, "Fourier Transform Infrared Spectroscopic Analysis of Protein Secondary Structures," Acta Biochimica et Biophysica Sinica 39(8), 549-559 (2007).

30. P. Garidel, H. Schott, "Fourier-Transform Midinfrared Spectroscopy for Analysis and Screening of Liquid Protein Formulations Part 2: Detailed Analysis and Applications," Bioprocess International 1, 48-55 (2006).

31. A. Barth, C. Zscherp, "What vibrations tell about proteins," Quarterly Reviews of Biophysics 35(4), 369-430 (2002).

32. R. Khurana, A. L. Fink, "Do parallel beta-helix proteins have a unique fourier transform infrared spectrum?" Biophysical Journal 78(2), 994-1000 (2000).

33. A. Dong, W. S. Caughey, "Infrared methods for study of hemoglobin reactions and structures," Methods in Enzymology 232, 139-175 (1994).

34. R. I. Litvinov, D. A. Faizullin, Y. F. Zuev, and J. W. Weisel, "The $\alpha$-helix to $\beta$-sheet transition in stretched and compressed hydrated fibrin clots," Biophysical Journal 103, 1020-1027 (2012).

35. A. Roque, I. Iloro, I. Ponte, J. L. R. Arrondo, and P. Suau, "DNA-induced secondary structure of the carboxylterminal domain of histone H1," Journal of Biological Chemistry 280(37), 32141-32147 (2005).

36. S. Venkataramani, J. Truntzer, and D. R. Coleman, "Thermal stability of high concentration lysozyme across varying pH: A Fourier Transform Infrared study," Journal of Pharmacy \& Bioallied Sciences 5(2), 148-153 (2013).

37. C.-Y. Lin, M.-C. Yang, "Improved p-Value Tests for Comparing Two Independent Binomial Proportions," Communications in Statistics-Simulation and Computation 38(1), 78-91 (2008).

38. M. D. C. Martínez-Ballesta, P. García-Gomez, L. Yepes-Molina, A. L. Guarnizo, J. A. Teruel, and M. Carvajal, "Plasma membrane aquaporins mediates vesicle stability in broccoli," PLoS One 13(2), e0192422 (2018).

39. L. M. Miller, M. W. Bourassa, and R. J. Smith, "FTIR spectroscopic imaging of protein aggregation in living cells," Biochimica et Biophysica Acta (BBA) - Biomembranes 1828(10), 2339-2346 (2013).

40. M. Svensson, J. Fast, A.-K. Mossberg, C. Düringer, L. Gustafsson, O. Hallgren, C. L. Brooks, L. Berliner, S. Linse, and C. Svanborg, "Alpha-lactalbumin unfolding is not sufficient to cause apoptosis, but is required for the conversion to HAMLET (human alpha-lactalbumin made lethal to tumor cells), " Protein Science 12(12), 2794-2804 (2003). 